\title{
Nocturnal activities and host preferences of Phlebotomus orientalis in extra-domestic habitats of Kafta-Humera lowlands, Kala-azar endemic, Northwest Ethiopia
}

Wossenseged Lemma ${ }^{1,2^{*}}$, Habte Tekie ${ }^{2}$, Ibrahim Abassi ${ }^{3,4}$, Meshesha Balkew ${ }^{5}$, Teshome Gebre-Michael ${ }^{5}$, Alon Warburg ${ }^{3,4}$ and Asrat Hailu ${ }^{6}$

\begin{abstract}
Background: Phlebotomus orientalis feeds on a variety of wild and domestic animals and transmits Leishmania donovani from hitherto unknown reservoir hosts to humans in extra-domestic habitats in the Metema - Humera lowlands. The aim of this study was to determine the nocturnal activities of $P$. orientalis and its preferred blood meal hosts.

Methods: Collections of Phlebotomus orientalis were made by using CDC light traps to determine the density as P. orientalis/hour CDC trap and preference to rodents by using Turners traps in agricultural fields, animal shelters and thickets of Acacia seyal in Baeker site-1 and Gelanzeraf site-2. The blood meal sources were detected by Reverse Line Blot (RLB) of cytochrome $b$ polymerase chain reaction (PCR) amplification in August, 2012 from collections of sand flies in thickets of A. seyal (March 2011) and dense mixed forest (July 2011) in Baeker site 1. RLB PCR involved first amplification of animal specific sequences of cytochrome $b$ using PCR techniques. Then the amplified sequence was hybridized with 11 species-specific probes for domestic animals adsorbed on nitrocellulose membrane for calorimetric color detection.

Results: A total of 6,083 P. orientalis (2,702 males and 3,381 females) were collected at hourly intervals using 22 CDC traps from January to May 2013. The peak activities of $P$. orientalis were at 1.00 a.m (134.0 7.21) near animal shelters, 3.00 a.m (66.33 46.40) in agricultural fields and 21:00 pm (40.6 30.06) in thickets of A. seyal. This species was not attracted to the different species of rodents in trials carried out in March and April 2013. RLB PCR identified 7 human (28\%), 9 mixed (human and cattle) (36\%) and 2 cattle (8\%) blood meals while 7 were unknown (28\%).

Conclusion: Female $P$. orientalis can bite humans in extra-domestic habitats of Kafta-Humera lowlands at any hour of the night with peak biting after midnight.
\end{abstract}

Keywords: Nocturnal activities, Host preferences, Phlebotomusm orientalis, Extra-domestic habitats, Kala-azar, Kafta Humera lowlands, Northwest Ethiopia

\footnotetext{
* Correspondence: wossensegedlemma@yahoo.com

${ }^{1}$ Department of Parasitology, School of Biomedical \& Laboratory Sciences, College of Medicine and Health Sciences, University of Gondar, Gondar,

Ethiopia

${ }^{2}$ Department of Zoological Sciences, College of Natural Science, Addis Ababa

University, Addis Ababa, Ethiopia

Full list of author information is available at the end of the article
}

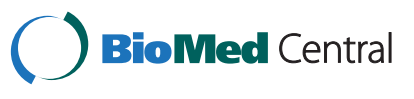

2014 Lemma et al.; licensee BioMed Central. This is an Open Access article distributed under the terms of the Creative Commons Attribution License (http://creativecommons.org/licenses/by/4.0), which permits unrestricted use, distribution, and reproduction in any medium, provided the original work is properly credited. The Creative Commons Public Domain Dedication waiver (http://creativecommons.org/publicdomain/zero/1.0/) applies to the data made available in this article, unless otherwise stated. 


\section{Background}

Of the total half a million kala-azar (Visceral Leishmaniasis; VL) cases in the world, 90\% occur in Bangladish, India, Nepal, Sudan, Ethiopia and Brazil [1]. In Sudan and northwest Ethiopia, kala-azar is transmitted by $P$. orientalis [2-4] and it claims the lives of thousands of people [5-7]. Phlebotomus orientalis is found to exhibit anthropophilic behavior and it transmits VL from man to man and/ or to dog and vice versa $[8,9]$. The dog was considered as an intermediate host between a possible sylvatic cycle and the anthroponotic cycle [9]. The large numbers of patients with post kala-azar dermal leishmaniasis (PKDL) in heavily affected villages in Sudan might also indicate a possible human reservoir and anthroponotic transmission [10]. Phlebotomus orientalis was also reported to be exophagic/exophilic (zoonotic VL) [9-13]. Zoonotic transmission of VL in east Africa was also suggested based on evidence of VL outbreaks among people that camped in uninhabited areas of eastern and former southern Sudan in addition to isolation of $L$. donovani from wild animals in the uninhabited Dinder National Park [14-16]. Experimental study on host preferences of $P$. orientalis and the isolation of $L$. donovani in east Africa have indicated that Canis familiaris (dogs), Herpeistes ichneumon (mongoose), Genetta genetta (genet cat), Acomys spp. and Arvicanthis spp. as preferred hosts for source of blood meals $[2,13,17,18]$. The result of $P$. orientalis from human bait also showed humans to be preferred hosts [4,19-21]. Attraction of $P$. orientalis towards cattle, sheep, goat, mule, donkey and horse has not been defined in east Africa as a whole, even though high Leishmania seroprevalence rate for these domestic animals has been reported in eastern Sudan [22] and northwest Ethiopia [23].

In the Metema-Humera lowlands, seasonal labour migrants who stay in agricultural fields for weeding and harvest of sesame, sorghum and cotton are exposed to Zoonotic kala-azar infections from June to October [24]. In these areas, the nocturnal activities (dieal periodicity) and the peak biting hours of $P$. orientalis were not studied. Adequate knowledge on these aspects helps to reduce kala-azar incidence by avoiding contact with sand flies at that particular period. Information on the host preferences of this vector could also give important clues in identification of reservoir hosts of kala-azar. Thus the aim of this study was to elucidate the nocturnal activities and host preferences of $P$. orientalis in Kafta Humera lowlands.

\section{Methods}

\section{Study area}

Kafta-Humera, Welkait and Tsegede are three districts in the Western Zone of Tigray region and the vast land at an altitude of around $600 \mathrm{~m}$ above sea level, which is endemic to kala-azar. Humera town (1417 N, 03639 E; altitude $637 \mathrm{~m}$ ) is the capital of Kafta-Humera district and it is the sit for the administrative centers of the district and the Zone. It is bordered to Eritrea in the north and Sudan in the west. It is located $180 \mathrm{~km}$ west of Shirao town (Tahatay Adiyabo district of Tigray region) and $253 \mathrm{~km}$ northwest of Gondar town (Amhara region). Kafta-Humera district has a total population of 92,167 (47,909 men and 44,258 women) and covers an area of 4, 542.33 square $\mathrm{km}$ [25]. In the district small towns such as Rawyan $\left(1417^{\prime} \mathrm{N}, 3637\right.$ 'E), May Kadra (1408 ' $\mathrm{N}, 3634$ ' E), Baeker $\left(1400^{\prime} \mathrm{N}\right.$; 3661 'E) and Adebay $(1417$ 'N, 3638 'E) are surrounded by uniform agricultural fields that are occasionally interrupted by thickets of Acacia seyal in depressions. All the dense mixed forests were converted into agricultural fields except in the Kafta Shiraro Park and some rocky outcrops. The part of the dense mixed forest in Baeker is used for grazing of domestic animals especially during the rainy season when all arable land is covered with crops. The common trees and shrubs in Kafta-Humera areas are A. seyal, A. mellifera, Balanites aegyptiaca, Terminalia spp., Boswellia papyrifera, Ficus sycomorus, Sclerocarya birrea, Zizypus spp., Dalbergia melanoxylon, Boscia angustifolia, Sterculia africana, Adansonia digitata, Dichrostachys cineria and Syzgium guineese.

The study was conducted in two selected extra-domestic sites. These were Baeker town (Site 1) and Gelanzeraf (Site 2). The former is a small town located $40 \mathrm{~km}$ from Humera town on the asphalt road leading to Gondar. Baeker extra-domestic sand fly sampling Site 1 (1401 N, $3659 \mathrm{E}, 651 \mathrm{~m}$ ) is located $33 \mathrm{~km}$ from Humera town close the main road between Humera and Gondar towns. Gelanzeraf is a locality southwest of Humera, near the Sudan boarder. Gelanzeraf extra-domestic sampling Site 2 $(1359 \mathrm{~N}, 03631 \mathrm{E})$ is located at $38 \mathrm{~km}$ from Humera town near the new asphalt road leading to Sudan, at about $20 \mathrm{~km}$ from the Sudan border (Figure 1). In both sites, there were closely placed huts (tukuls) in the camps on the agricultural fields. Domestic animal shelters are located at about $200 \mathrm{~m}$ in Site 1 and $250 \mathrm{~m}$ in Site 2 from the huts. Acacia seyal in Site 1 is located about $2 \mathrm{~km}$ from the huts compared with $4 \mathrm{~km}$ in Site 2 . In Site 1, the two vacant huts were giving service only during agricultural rainy season. The 4 guards near telecommunication bare (tower) and 4 animal keepers near the animal shelters were the only persons near the huts in Site 1 in addition to 3 individuals working on irrigation of vegetables, using ground water in a gorge found slightly far away from the huts. One individual, of those working in the irrigation, left the area following kala-azar infection in September, 2011, after completing treatment in Humera Kahsaye Abera hospital. In Site 2, the camp has 3 huts and a big store with 5 individuals who take care of the area and the animals. 


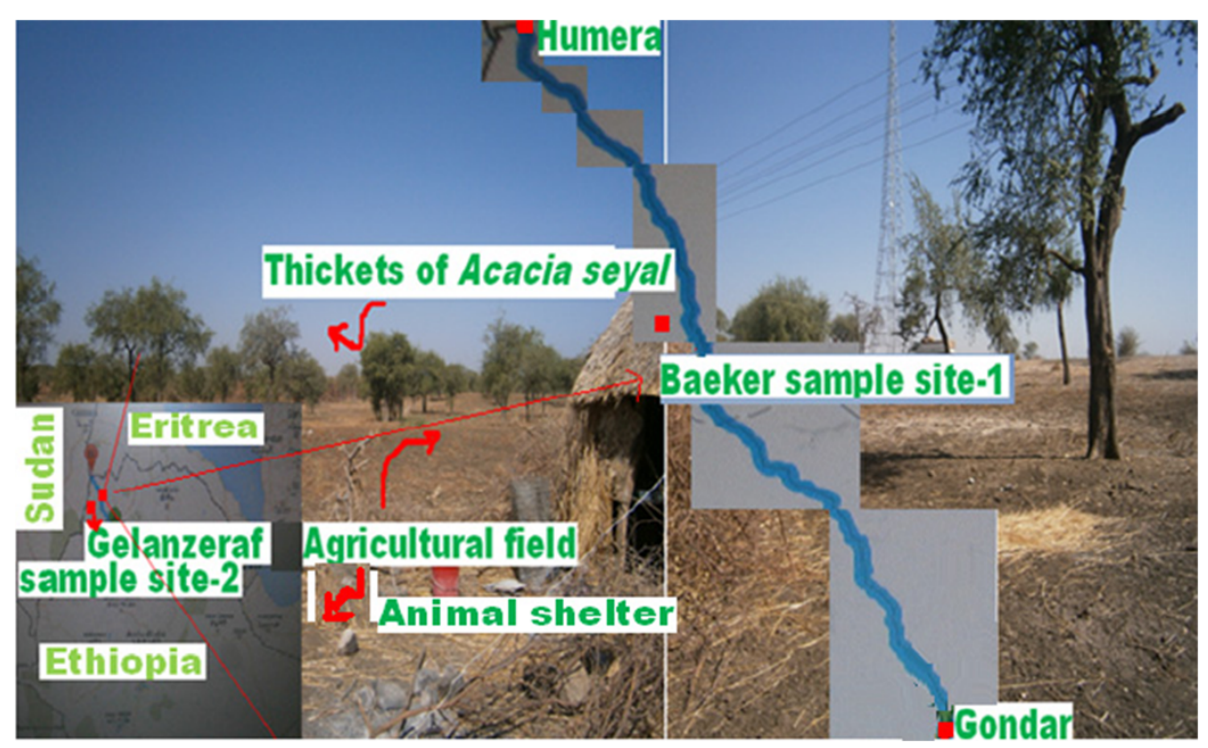

Figure 1 Agricultural field, animal shelter and thickets of Acacia seyal sampling points in Baeker site 1, where collections of sand flies for the studies of nocturnal activities and host preference towards rodents were conducted from January to May 2013.

Goats and sheep are browsing and grazing in agricultural fields and sparse thickets of $A$. seyal including the dense mixed forest (Part of Kafta-Shirao park in Baeker at about $7 \mathrm{~km}$ from Site 1) during the day and shelter near the camps at night unlike cattle which grazed at night during dry season (October - June). In agricultural rainy season, however, animals are guarded in the dense mixed forest and rocky uncultivated areas. Similar points on agricultural fields, animal shelter and sparse thickets of $A$. seyal were selected for the repeated sand fly collections during studies of nocturnal activities and host preference towards rodents. The sampling points on agricultural fields and animal shelter were separated by about $400 \mathrm{~m}$ with the huts located between them in both Site 1 and 2. The sampling point for animal shelter was about $2 \mathrm{~m}$ from where the goats and sheep sheltered in both sites.

\section{Habitats}

The vegetations in Metema-Humera lowlands on black cracking soil were described as Acacia seyal - Balanites aegyptiaca forest and Argeissus - Combretum savannah woodlands [26], which have been transformed into big agricultural fields. During transformation of forest into fields, all trees except Balanites aegyptiaca were cleared in order to prevent gully erosion. Thus, agricultural fields in these areas have this tree species at about $25 \mathrm{~m}$ intervals (Figure 1). The soil in the study sites was black soil (eutric vertisols) [27] also reported to be associated with $P$. orientalis and kala-azar in Ethiopia and adjacent Eritrea and Sudan [2,12,27-29]. It is thought that such soil is hygroscopic and swells during the rainy season, then loses water and shrinks quickly during the dry season resulting in very deep cracks, creating essential microhabitats for the vector, $P$. orientalis [27,30]. Vertisol at shallow depths $(45 \mathrm{~cm})$ near Balanites aegyptiaca with relatively cool temperature, stable humidity and enhanced soil decomposition rate, were reported as suitable breeding site for sand fly larvae compared to open fields with seasonal 5 6C temperature and $38.07 \%$ (average) relative humidity fluctuations [30]. The annual mean maximum temperature in Baeker and Humera towns vary from 29.10 to $41.2 \mathrm{C}$ while the monthly mean minimum range from 13.50 to $25.40 \mathrm{C}$ with November to May being the dry season that is characterized by high mean maximum temperatures (35.7 40.83C), lack of heavy rain and cracking of black soil. March, April and May were the hottest months with mean maximum temperatures ranging from 38.9 to $40.83 \mathrm{C}$. The rainy season started in May and extended up to October with the highest rainfall occurred in August (Mean SD: 199.97 126.53). Average annual rainfall received by the area from 2011 to 2013 was $791 \mathrm{~mm}$ [31].

\section{Nocturnal activities of Phlebotomus orientalis}

A total of 22 CDC light traps were deployed on agricultural fields $(\mathrm{n}=11)$, animal shelters $(\mathrm{n}=3)$ and thickets of sparse A. seyal $(\mathrm{n}=8)$, during January May, 2013, to collect sand flies at one hourly intervals by changing sand fly cages before they were kept in separate tubes containing 96\% ethanol for subsequent species identification. After Sergentomyia spp. were separated, Phlebotomus spp. 
were identified by using appropriate keys [32-34] following dissection and mounting of the specimens using Hoyer s medium.

\section{Host preference of Phlebotomus orientalis using small rodents in Turner and Hoogstraal $s$ box traps}

In order to evaluate the host preference of $P$. orientalis towards rodents, locally made box traps based on the design of Turner \& Hoogstraal [35] were used. A total of 30 rodents (2 Rattus spp., 18 Arvicanthis spp., 4 Tatera spp., and 6 Acomys spp.) in 30 box traps were used as baits in Site 1 and 2 agriculture fields $(\mathrm{n}=10)$, animal shelter $(\mathrm{n}=10)$ and thickets of $A$. seyal $(\mathrm{n}=10)$ for a total of 10 days in March and April, 2013.

\section{Blood meal analysis of Phlebotomus orientalis using Reverse Line Blot (RLB) of cytochrome $b$ PCR product Sand fly collection and preservation}

Any freshly blood-fed female $P$. orientalis encountered during previous sand fly collection from thickets of $A$. seyal (March, 2011) and dense mixed forest (July, 2011) in Baeker, was preserved for molecular identification of animal species that served as source of blood for this vector using Reverse Line Blot (RLB) of cytochrome $b$ PCR product. For this purpose, the head of each fed female was mounted on the slides by Hoyer s medium for later species identification. The remaining body (thorax and abdomen) was individually placed in empty sterile eppendorf tube with silica gel grains and cotton pads inside, bearing a corresponding label with the mounted specimen on the slide. They were stored at $-20 \mathrm{C}$ until molecular blood meal analysis was conducted in August 2012 in the Department of Microbiology \& Molecular Genetics, Hadassah Medical School, Hebrew University, Israel.

\section{DNA extraction}

The thorax and abdomen of freshly-fed $P$. orientalis from each tube with silica gel were placed on filter and were transferred to test tube for digestion of tissues using lysis buffer $(200 \mu \mathrm{l})$ and proteinase K $(10 \mu \mathrm{l})$. Each Phlebotomus orientalis was homogenized using sterile wooden sticks and incubated in water bath (65C) for 2 hours. Phenol extraction of DNA was made by adding $180 \mu \mathrm{l}$ phenol before centrifugation at maximum speed (1,400 r.p.m) for 2.5 minutes. For ethanol DNA extraction, the aqueous part $(150 \mu \mathrm{l})$ was transferred into a test tube containing sodium chloride solution $(8 \mu \mathrm{l})$ before $400 \mu \mathrm{l}$ cold $(-20 \mathrm{C})$ ethanol was added and placed in refrigerator $(-20 \mathrm{C})$ for 2 hours and cold centrifugation at maximum speed (1400 r.p.m) for 10 minute that precipitated DNA. Finally, pure DNA was obtained by removing the ethanol and suspending in $50 \mu$ l double distilled water.

\section{Species-specific probes}

This study described a blood meal identification approach based on PCR amplification of the mitochondrial cytochrome $b$ gene (cyt $b$ ) followed by RLB analysis as already described [36,37]. RLB is a highly reproducible technique in which species-specific oligonucleotides (probes) are covalently linked to nylon membranes through the formation of amide bonds between the carboxyl group present on the membrane and amino-linked oligonucleotides which hybridizes with Biotinylated PCR products of the mitochondrial cyt $b$ gene to reveal color that will be detected by colorimetric or enhanced chemiluminescent (ECL) systems. The species-specific oligonucleotide probes designed by Abassi et al. [36] for human (ATG CAC TAC TCA CCA GAC GC), cattle (ATT ATG GGT CTT ACA CTT T), sheep (TCC TAT TTG CGA CAA TAG CTT CCT), goat (ATA CAT ATC GGA CGA GGT CTA), camel (CGT TGG AAT TGT TTT ATT), donkey (CTA CTT TTC ACA GTT TAG CTA CA), dog (CAG ATT CTA ACA GGT TTA ), mouse (TGG AGT ACT TCT ACT GTT CGC AGT), rat (CAG TCA CCC ACA TCT GC), chicken (CAT CCG GAA TCT CCA C) and avian (TAC ACA GCA GAC AC) were used which adsorbed on the $34 \mathrm{~mm}$ strips of membrane in the following order from the top to bottom: Human, donkey, cattle, sheep, goat, camel, dog, mouse, rat, chicken and avian. One probe was found effective in identification of any avian species (36).

\section{Polymerase chain reaction}

To make $25 \mu \mathrm{l}$ of final volume for PCR reaction, $20 \mu \mathrm{l}$ master mix $(1 \mu$ l forward primer, $1 \mu$ l backward primer and $18 \mathrm{ddH}_{2} \mathrm{O}$ ) and $5 \mu \mathrm{l}$ DNA sample were mixed. PCR amplification of the mitochondrial cytochrome $b$ gene was made using primers Cyto1 (5'-CCA TCA AAC ATC TCA GCA TGA TGA AA-3') and Cyto2 (5'- CCC CTC AGA ATG ATA TTT GTC CTC-3') before gel electrophoresis at $120 \mathrm{~V}$ in 1 TAE buffer in $1.5 \%$ agarose gels. The DNA fragments were visualized by UV light for determination of the sizes. The PCR product left from gel electrophoresis $(18 \mu \mathrm{l})$ was used for RLB hybridization.

\section{RLB hybridization}

Species-specific probes from the 11 species were bounded on $5.515 \mathrm{~cm}$ biodyne C membrane (Gelman, USA).

The species-specific probes were adsorbed on the membrane so that they would identify the corresponding PCR product indicating the species of animals $P$. orientalis fed. The membrane was first incubated with $0.1 \mathrm{M} \mathrm{HCl}$ and $10 \%$ EDAC solution before the bounding of probes and was later cut into strips of $34 \mathrm{~mm}$ width for the process of sample hybridization. 


\section{Statistical analysis}

The nocturnal activities of $P$. oreintalis during 12 hours of the night were estimated from mean number $P$. orientalis/hour/CDC. All statistical analyses were performed using the Statistical Package of Social Science (SPSS), version 16. Comparisons of nocturnal activities during the night hours were analyzed using one-way analysis of variance (ANOVA). P-values less than 0.05 for mean number $P$. orientalis/hour/CDC were considered as significantly different.

\section{Results}

\section{Population dynamics of Phlebotomus orientalis}

A total of 6,083 P. orientalis (3,381 females and 2,702 males) was collected at one hour interval for 18 nights using a total of $22 \mathrm{CDC}$ traps from agricultural fields near the camps $(1,989$ females and 1,614 males; $n=11$
CDC traps), sparse thickets of $A$. seyal (167 females and 738 males; $\mathrm{n}=8 \mathrm{CDC}$ traps) and near sheep and goat shelters (1,349 females and 573 males; $\mathrm{n}=3$ CDC traps) during the study period. Phlebotomus papatasi (18), $P$. duboscqi (9), P. begeroti (7) and P. rodhaini (6) were other species of Phlebotomus collected with the same traps. Overall 20,236 (10,211 males and 10,025 females) Sergentomyia spp. were collected. The highest overall mean number of $P$. orientalis/hour/CDC trap was collected from animal shelters (53.37 45.80) and followed by agricultural fields (28.87 23.45). The lowest mean number of $P$. orientalis/hour/CDC trap was found from thickets of $A$. seyal (9.60 16.38) (Figure 2). Nocturnal activities of female $P$. oriental were significantly different among the hours of the night in the agricultural fields $(p=0.023)$ and animal shelters $(\mathrm{p}=0.001)$. However, no significant difference was found for the activities of $P$. orientalis at the

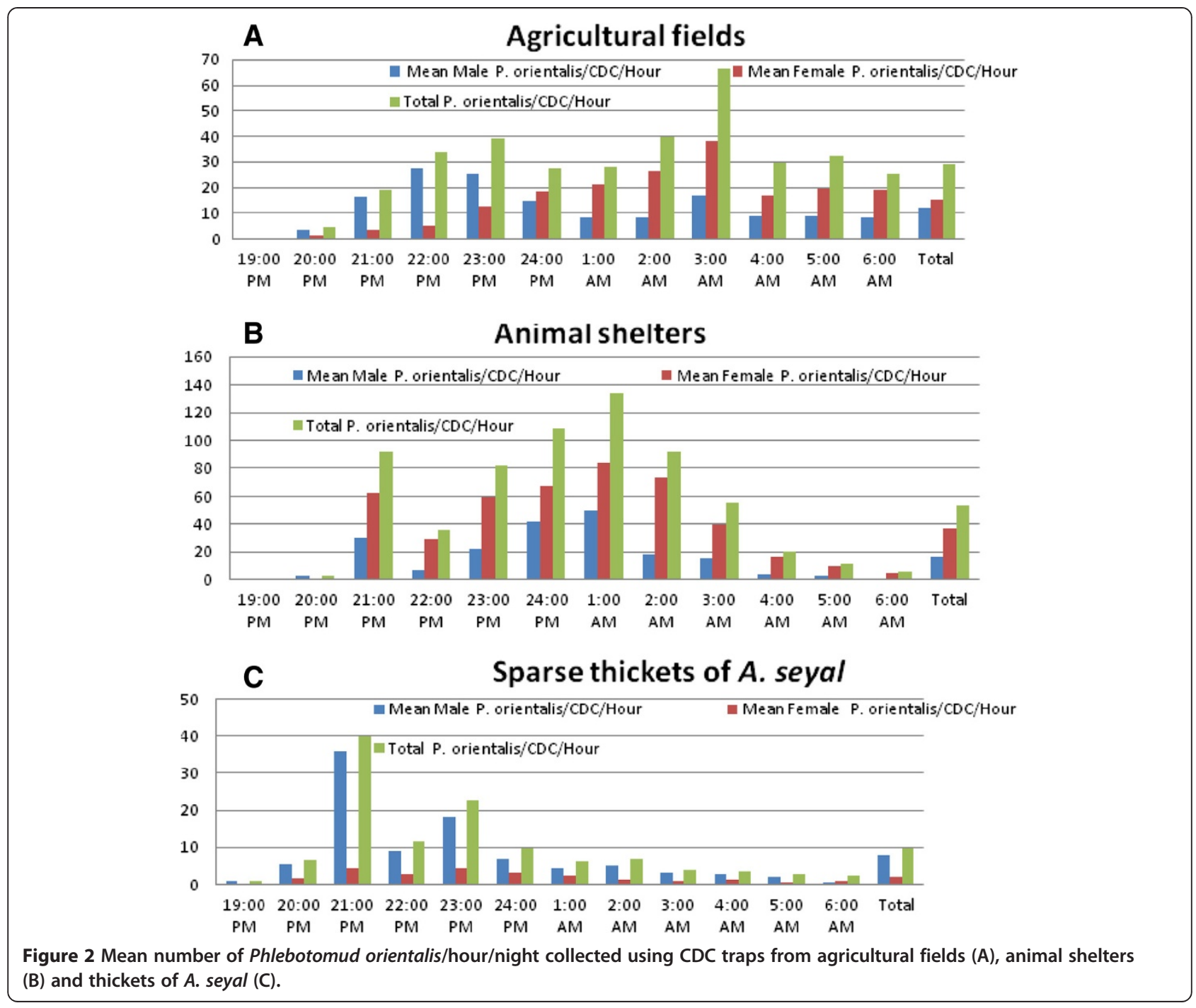


different hours of the night in the thickets of Acacia seyal $(\mathrm{p}=0.144)$. The peak activities of $P$. orientalis were at 1.00 a.m. near animal shelters (134.0 7.21), 3.00 a.m. (66.33 46.40) in the agricultural fields and 21.00 p.m. (40.06 30.06) in thickets of A. seyal. The overall sex ratios of $P$. orientalis in agricultural field (1.30 female: 1 male), animal shelter ( 2.35 female: 1 male) and thickets of $A$. seyal (1 female: 4.42 male) were different. Thus, $P$. orientalis collections were male biased in thickets of $A$. seyal and female biased in around the camps.

\section{Host preference of Phlebotomus orientalis towards rodents using Turner and Hoogstraal $s$ traps}

No $P$. orientalis was collected in rodent baited Turner Box s trap. Only 5 Sergentomyia species (S. schwetzi) were collected from 30 Turner s box trap deployed for 10 days in the agricultural fields, animal shelters and thickets of $A$. seyal in both sites.

\section{Host preference study of Phlebotomus orientalis based on molecular analysis of blood meals}

Only humans and cattle were found as the source of blood meals for $P$. orientalis collected from $A$. seyal and dense mixed forest in Baeker Site 1 from March to July 2011 when hybridization of PCR products of cytochrome $b$ and the species specific probes was carried out. Of the 25 blood-fed $P$. orientalis analyzed using cyt $b$ PCR and RLB (Figure 3), 7 (28\%) were human, 9 mixed human and cattle (36\%) and 2 cattle (8\%). There were 7 samples (28\%) with bands on agarose gel but not in nitrocellulose membrane indicating the existence of other animals outside the 11 probes.

\section{Discussion}

So far no effective VL control measures have been conducted in Sudan and northwest Ethiopia, mainly due to the sylvatic nature of the habitats of adult $P$. orientalis and the lack of enough knowledge on transmission dynamics of $L$. donovani between unknown reservoir hosts and humans [38]. Studies on nocturnal and feeding activities of adult $P$. orientalis could give an insight about the behavior of this vector which is an essential component to design kala-azar control strategies. The results on nocturnal activities from hourly CDC and molecular blood meal analysis showed a risk of $P$. orientalis bite throughout the night as already reported [11]. Use of bed net by labour migrants involved in agricultural activities in the study areas is required.

The fact that the highest mean value of $P$. orientalis collected near animal shelters might indicate that goats and sheep were also sources of blood meals. The role of goats and sheep in the epidemiology of kala-azar is a subject of further study. Only one serological study in eastern Sudan indicated $8.5 \%$ L. donovani infection rate in goats using DAT [22]. In Kenya, P. duboscqi and $P$. martini were reported to be attracted to goats [39]. Recently, RLB of cytochrome $b$ PCR products of blood meal collected from $P$. orientalis in domestic areas in Kafta-Humera district showed goats and sheep as a source of blood meal for this vector in addition to cattle (Yared et al., personal communication). The mean landing rate on human bait near goat and sheep shelters was almost twice the rates in the agricultural fields. Thus, goats and sheep might have zooprophylactic effect in preventing humans from kala-azar as, e.g. cattle [21]. This study has also shown that cattle to be important source of

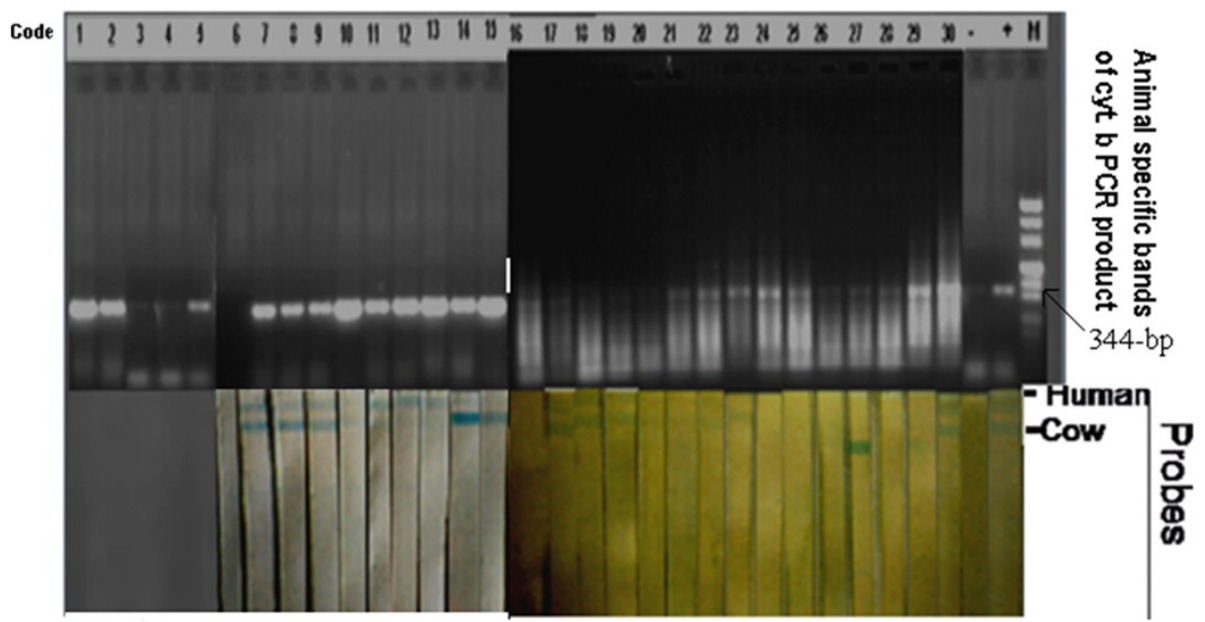

Figure 3 Animal s specific bands of cytochrome b PCR products (344-bp) obtained from blood meals of Phlebotomus orientalis on gel-electrophoresis after visualized by UV light (Top) and species specific hybridization of the PCR products obtained from different fresh fed $P$. orientalis using the different probes on nitrocellulose (bottom). Only Human and cattle were found as source of blood meal for P. orientalis collected from Acacia seyal (March 2011) and dense mixed forest (July 2011) in the beaker site 1. 
blood for $P$. orientalis in extra-domestic habitats where $72 \%$ of this species was found to have human and/or cattle blood-meal source. Mixed (human and cattle) blood meal was found to be very high (36\%) which might indicate that $P$. orientalis had interrupted feeding on both hosts. Interruptions might have occurred due to inherent behavior of the female fly or due to the physical disturbance by the human or cattle hosts during the probing of the fly. Previous study has shown that cattle serve as the main source of blood for P. orientalis in domestic areas [23]. The reason why more cattle (92\%) served as source of blood than human $(2.2 \%)$ in domestic and predomestic areas using Enzyme Linked Immuno Sorbent Assay (ELISA) [23] in the area of Metema compared with this study is difficult to explain, but might need further investigation.

The bands of DNA fragments (cyt. b) on agarose gel (28\%), that were not captured by the 11 probes used, may represent wild animals in the area. The probes that were not used include wild rodents and small carnivores. The existences of small carnivores such as genet cats and mongoose were confirmed during our study on reservoirs in these areas especially in the dense mixed forest (unpublished data). Either rodents or small carnivores or both could be the unknown source of blood for $P$. orientalis. Attractiveness towards mongoose (63.9 12.1/ $\mathrm{CDC} /$ night), genet cat (17.4 3.72/CDC/night) and Nile rat (2.6 $0.56 / \mathrm{CDC} /$ night) compared to the control $(0.4$ $0.16 / C D C /$ night) were reported in eastern Sudan [13]. No $P$. orientalis or other sandfllies were attracted to the rodents from all Turner and Hoogstraal box traps in this study. Similar study using CDC or sticky traps is required before reaching a conclusion.

The results of this study were in complete agreement with other observations $[11,40]$ showing night-long human bite of $P$. orientalis. The nocturnal activities and human biting behavior was described as wave-like to show non-uniformity of biting rate at different hours of the night [11]. Such wave-like biting was due to the effect of wind. There were different trends of winds according to the observations during this study. Sometimes it began at 19:00 pm and ended at 21:00 p.m. or started at 21:00 p.m. and came down at 23:00 or 24:00 p.m. In few instances strong wind persisted until 24:00 p.m. Having understood this, long study period was used as the probability of unsuccessful sand fly collection was high.

\section{Conclusion}

Phlebotomus orientalis could bite humans at different hours of the night and there is a risk of kala-azar infection in agricultural fields, thickets of $A$. seyal and in the camps. It is also attracted to domestic animals in the extradomestic habitats for blood meal. Phlebotomus orientalis is most probably catholic in its feeding habits and having wide range of mammals as blood meal sources depending on the available host in space and time. Whether these animals are potential carriers of Leishmania causing Kala-azar needs further investigation.

\section{Recommendations}

Despite several attempts made to investigate the reservoir host of $L$. donovani in Sudan and northwest Ethiopia, further study, with more emphasis on wild animals in extradomestic animals, are required.

\section{Competing interests}

The authors declare that they have no competing interests.

\section{Authors contributions}

$W L, H T, M B, T G, A W$ and $A H$ designed the research and prepared the proposal. WL did sand fly collection, processing, data analysis and preparation of this manuscript. $H T, M B, T G, A W$ and $A H$ supervised the overall activities. IA and WL conducted the molecular analysis. HT, MB and TG reviewed the manuscript. All authors read and approved the final manuscript.

\section{Acknowledgements}

We would like to thank the Bill and Melinda Gates Foundation Global Health Program [Grant number OPPGH5336] and Gondar University for funding this research. We would also thank Abel Haile, for technical assistance and for sand fly sampling, and Shewangizaw Sime (driver) and all who assisted us during our field activities in Metema Humera low lands. Our thanks also go to Tigray regional state and western Tigray zone administration for their unreserved co-operation during the execution of this research.

\section{Author details}

${ }^{1}$ Department of Parasitology, School of Biomedical \& Laboratory Sciences, College of Medicine and Health Sciences, University of Gondar, Gondar, Ethiopia. ${ }^{2}$ Department of Zoological Sciences, College of Natural Science, Addis Ababa University, Addis Ababa, Ethiopia. ${ }^{3}$ Department of Microbiology \& Molecular Genetics, The Institute for Medical Research Israel-Canada, Jerusalem, Israel. ${ }^{4}$ The Kuvin Centre for the Study of Infectious \& Tropical Diseases, The Hebrew University Hadassah Medical School, The Hebrew University of Jerusalem, Jerusalem 91120, Israel. ${ }^{5}$ Aklilu Lemma Institute of Pathobiology, Addis Ababa University, Addis Ababa, Ethiopia. ${ }^{6}$ Department of Microbiology, Immunology \& Parasitology, Faculty of Medicine, Addis Ababa University, Addis Ababa, Ethiopia.

Received: 28 September 2014 Accepted: 6 December 2014 Published online: 17 December 2014

\section{References}

1. Chappuis F, Sundar S, Hailu A, Ghalib H, Rijal S, Peeling RW, Alvar J, Boelaert M: Visceral leishmaniasis: what are the needs for diagnosis, treatment and control? Nat Rev Microbiol 2007, 5:873 82

2. Hoogstraal H, Heyneman D: Leishmaniasis in the Sudan Republic. 30. Final epidemiological report. Am J Trop Med Hyg 1969, 18:1091 1210.

3. Gemetchu T, Zerihune A, Assefa G, Lemma A: Observations on the sandfly (Phlebotomidae) fauna of Setit-Humera (Northwestern Ethiopia). Ethiop Med J 1975, 13:41 51.

4. Elnaiem DA, Hassan HK, Ward RD: Phlebotomine sandflies in a focus of visceral leishmaniasis in a border area of eastern Sudan. Ann. Trop. Med. Parasitol 1997, 91:307 318.

5. Seaman J, Mercer J, Sondorp E: The epidemic of visceral Leishmaniasis in Western Upper Nile, southern Sudan: course and impact from 19841994. Int J Epidemiol 1996, 25:862 871.

6. Hailu A, Gebre-Michael T, Berhe N, Balkew M: Leishmaniasis. In Epidemiology and Ecology of Health and Disease in Ethiopia Shama Books. Edited by Berhane Y, Hailemariam D, Kloos H. Addis Ababa: 2006:615 634.

7. Ritmeijer K, Dejenie A, Assefa Y, Hundie B, Mesure J: A comparison of miltefosine and sodium stibogluconate for treatment of visceral leishmaniasis in an Ethiopian population with high prevalence of HIV infection. Clin Infect Dis 2006, 43:357 364. 
8. Lambert M, Dereure J, El-Sail SH, Bucheton B, Dessein A, Boni M, Feugier E, Dedet JP: The sandfy fauna in the visceral leishmaniasis focus of Gedaref, in the Atbara-river area of eastern Sudan. Ann Trop Med Parasitol 2002, 96:631 636.

9. Dereure J, El-Safi H, Bucheton B, Boni M, Kheir M, Davoust B, Pratlong F, Feugier E, Lambert M, Dessein A, Dedet J: Visceral leishmaniasis in eastern Sudan: parasite identification in humans and dogs; host-parasite relationships. Microbes Infect 2003, 5:1103 1108.

10. Zijlstra EE, El-Hassan AM: Leishmaniasis in Sudan. Visceral leishmaniasis. Trans R Soc Trop Med Hyg 2001, 95:S27 S58.

11. Schorscher J, Goris M: Incrimination of Phlebotomus (Larroussius) orientalis as a vector of visceral leishmania sis in Western Upper Nile province, southern Sudan. Trans R Soc Trop Med Hyg 1992, 86:623 627

12. Elnaiem A, Conners S, Thmoson M, Hassan M, Hassan H, Aboud A, Ashford W: Environmental determinants of the distribution of Phlebotomusorientalis in Sudan. Ann Trop Med Parasitol 1998, 92:877 887.

13. Hassan M, Osman OF, El-Raba'a FM, Schallig HD, Elnaiem DE: Role of the domestic dog as a reservoir host of Leishmania donovani in eastern Sudan. Parasit Vectors 2009, 2:26.

14. Kirk R: Studies in leishmaniasis in the Anglo-Egyptian Sudan. XII. Attempts to find a reservoir host. Trans Roy Soc Trop Med Hyg 1956, 50:169 177

15. Ibrahim ME, Lambson B, Yousif AO, Deifalla NS, Alnaiem DA, Ismail A Yousif H, Ghalib W, Khalil AG, Kadaro A, Barker DC, El Hassan AM: Kala-azar in a high transmission focus: an ethnic and geographic dimension. Am J Trop Med Hyg 1999, 61:941 944.

16. Elnaiem DA, Hassan MM, Maingon R, Nureldin GH, Mekawi AM, Miles M, Ward RD: The Egyptian mongoose, Herpestes ichneumon, is a possible reservoir host of visceral leishmaniasis in eastern Sudan. Parasitology 2001, 122:531 536 .

17. Haile T, Lemma A: Isolation of Leishmania parasites from Arvicanthis Ethiopia. Trans Roy Soc Trop. Med Hyg 1977, 71:180 181.

18. Mutinga MJ, Ngoka JM, Schnur LF, Chance ML: The isolation and identification of leishmanial parasites from domestic dogs in Machakos District of Kenya, and possible role of dogs reservoirs of kala-azar in East Africa. Ann Trop Med Parasitol 1980, 74:139 144.

19. Ashford RW, Hutchinson MP, Bray RS: Kala-azar in Ethiopia: pidemiological studies in a highland valley. Ethiop Med J 1973, 11:259 264

20. Hailu A, Balkew M, Berhe N, Meredith E, Gemetchu T: Is Phlebotomus (Larroussius) orientalis a vector of visceral leishmaniasis in south-west Ethiopia? Acta Trop 1995, 60:15 20.

21. Kolaczinski $H$, Reithinger R, Dagemlidet T, Worku A, Ocheng K, Kabatereine K, Brooker S: Risk factors of visceral leishmaniasisin East Africa: a case control study in Pokot territory of Kenya and Uganda. Inter J Epidemiol 2008, 8:1 9.

22. Mukhtar AH, Sharief SH, El S, Harith AE, Higazz TB, Adam AM, Sulieman H: Detection of antibodies to Leishmania donovaniin animals in a kala-azar endemic region in eastern Sudan: a preliminary report. Trans $R$ Soc Trop Med Hyg 2000, 94:33 36

23. Gebre-Michael T, Balkew M, Berhe N, Hailu A, Mekonnen Y: Further Metema (north-west Ethiopia) with observations on their natural blood meal sources. Parasit Vectors 2010, 3:6.

24. WHO Expert Committee: Studies on Leishmaniasis vectors/Reservoirs and their control. The Old World, Tropical Africa. Geneva: World Health organization Technical Report Series; 1981:1 164.

25. Tigray Region report: Livelihood Profile Tigray Region, Ethiopia. Humera Sesame and Sorghum Livelihood Zone. Tigray Regional report. Mekele, Ethiopia: 2007:1 13.

26. Gemetchu T: The distribution of sandflies (Diptera, Psychodidae, Phlebotominae) in north-west Ethiopia. Sinet Ethiop J Sci 1983, 6:65 73

27. Gebre-Michael T, Malone JB, Balkew M, Ali A, Berhe N, Hailu A, Herzi AA: Mapping the potential distribution of Phlebotomus martini and $P$. orientalis (Diptera: Psychodidae), vectors of kala-azar in East Africa by use of geographic information systems. Acta Trop 2004, 90:73 86.

28. Fuller GK, Lemma A, Haile T, Gemeda N: Kala-azar in Ethiopia: survey of south-west Ethiopia. The leishmanin skin test and epidemiological studies. Ann Trop Med Parasitol 1979, 73:417 431.

29. Thomson MC, Elnaiem DA, Ashford RW, Connor SJ: Towards a kala-azar risk map for Sudan: mapping the potential distribution of Phlebotomus orientalis using digital data of environmental variables. Trop Med Int Health 1999, 4:105 113
30. Moncaz A, Kirstein O, Gebresellassie A, Lemma W, Yared S, Gebre-Michael T, Hailu A, Shenker M, Warburg A: Characterization of breeding sites of Phlebotomus orientalis The vector of visceral leishmaniasis in northwestern Ethiopia. Acta Trop 2014, 139:5 14.

31. Lemma W, Tekie H, Balkew M, Gebre-Michael T, Warburg A, Hailu A: Population dynamics and habitat preferences of Phlebotomus orientalis in extradomestic habitats of Kafta Humera lowlands kala azar endemic areas in Northwest Ethiopia. Parasit Vectors 2014, 7:359.

32. Abonnenc E, Minter DM: Bilingual keys for the identification of the sandflies of the Ethiopian region. Cah O R S T O M, ser. Entomol Med 1965, 5:3 24

33. Quate LW: Leishmaniasis in the Sudan Republic: Phlebotomus sandflies of the Paloich area in the Sudan (Diptera: Psychodidae). J Med Entomol 1964, 1:213 268

34. Lewis J: A taxonomic review of the genus Phlebotomus (Diptera: Psychodidae). Bull Brit Mus (Nat Hist) (Ent) 1982, 45:121 209.

35. Turner ER, Hoogstraal H: Leishmaniasis in the Sudan Republic. 23. Sandflies (Phlebotomus) attracted to rodent baited traps (Diptera: Psychodidae). J Med Entomol 1965, 2:137 139.

36. Abbasi I, Cunio R, Warburg A: Identification of blood meals imbibed by Phlebotomine sand flies using cytochrome $b$ PCR and reverse line blotting. Vec Borne Zoo Dis 2008, 2:280 285.

37. Garlapati RB, Abbasi I, Warburg A, Poch D, Poch R: Identification of bloodmeals in wild caught blood fed Phlebotomus argentipes (Diptera: Psychodidae) using cytochrome $b$ PCR and Reverse Line Blotting in Bihar, India. J Med Entomol 2012, 49:515 521.

38. Elnaiem DA: Ecology and control of the sand fly vectors of Leishmania donovani in East Africa, with special emphasis on Phlebotomus orientalis. J Vector Ecol 2011, 36:\$23 S30.

39. Mutinga MJ, Kyai FM, Kamau C, Omogo DM: Epidemiology of leishmaniasis in Kenya- host preference studies using various types of animal baits at animal burrows in Marigat, Baringo District. Insect Sci Appl 1986, 7:191 197.

40. Hoogstraal H, Dietlein DR, Hevneman D: Leishmaniasis in the Sudan Republic: 4. Preliminary observations on man-biting sand flies (Psychodidae: Phlebotoraus) in certain Upper Nile endemic areas. Trans Roy Soc Trop Med Hyg 1962, 56:411 422.

doi:10.1186/s13071-014-0594-3

Cite this article as: Lemma et al:: Nocturnal activities and host preferences of Phlebotomus orientalis in extra-domestic habitats of Kafta-Humera lowlands, Kala-azar endemic, Northwest Ethiopia. Parasites \& Vectors 2014 7:594.

\section{Submit your next manuscript to BioMed Central and take full advantage of:}

凶Convenient online submission

$\otimes$ Thorough peer review

$\bigotimes$ No space constraints or color $₫$ gure charges

$\otimes$ Immediate publication on acceptance

\Inclusion in PubMed, CAS, Scopus and Google Scholar

$\otimes$ Research which is freely available for redistribution 